\title{
Influence of human body geometry, posture and the surrounding environment on body heat loss based on a validated numerical model
}

\author{
Jingxian $\mathrm{Xu}^{\mathrm{a}}$, Agnes Psikuta ${ }^{\mathrm{b}}$, Jun $\mathrm{Li}^{\mathrm{a}, \mathrm{c}^{*}}$, Simon Annaheim ${ }^{\mathrm{b}}$, René M. Rossi ${ }^{\mathrm{b}}$ \\ ${ }^{a}$ Protective Clothing Research Center, College of Fashion and Design, Donghua University, Shanghai 200051, China \\ ${ }^{b}$ Empa, Swiss Federal Laboratories for Materials Science and Technology, Laboratory for Biomimetic \\ Membranes and Textiles, CH-9014, St. Gallen, Switzerland \\ ${ }^{c}$ Key Laboratory of Clothing Design and Technology, Donghua University, Ministry of Education, Shanghai \\ 200051, China
}

\begin{abstract}
For accurate prediction of human thermal comfort in indoor space, a fully validated human body-environment interface model is the key factor. In this study, a numerical model for heat transfer simulation between the human body and the environment was developed. Three parameters, including air speed, air temperature, and total heat transfer coefficient at the body surface, were validated against experiments including a manikin placed in a climatic chamber. Based on the verified model, a set of human body-environment parameters were investigated to quantify their relevance for thermal simulations. The parameters included three body geometries with different simplification levels, three body postures, and three kinds of environments differing in room configuration, size, and wall emissivity. The investigations revealed that body geometry simplification had only a moderate influence on overall heat transfer between the body and environment, while greatly influencing local heat transfer. Body posture showed a more prominent impact on heat transfer than the geometry, especially on the radiative heat transfer, due to the view factor change caused by local body orientation. The room configuration largely influenced the airflow pattern and, thus, convective heat transfer, while room size and wall emissivity only had an influence on radiative heat transfer. A similar environmental setup and body posture with the real situation would be suggested as the premise for the bodyenvironment modelling work. The validated numerical model, along with the set of body-environment parameters, can be used for a large range of investigations on human physiological response in varying thermal environments.
\end{abstract}

Keywords: human indoor thermal comfort, numerical simulation, heat transfer coefficient, human body geometry, human body posture, wall emissivity

\section{Introduction}

The design and evaluation of thermal conditioning systems indoors, as well as in automobile environments, is becoming a major research focus for saving energy. New economic solutions for building conditioning

This document is the accepted manuscript version of the following article:

Xu, J., Psikuta, A., Li, J., Annaheim, S., \& Rossi, R. M. (2019). Influence of human body geometry, posture and the surrounding environment on body heat loss based on a validated numerical mode1. Building and Environment, 166, 106340 (13 pp.). https://doi .org/10.1016/j.bui1denv.2019.106340 
and vehicle conditioning systems, such as zero-energy buildings and electric cars, are being developed handin-hand with the attempt to maintain thermal comfort of the occupants and users [1,2]. Human thermophysiological and thermal comfort responses, which reflect the thermal interaction between the human body and the surrounding environment, are considered important factors for the evaluation of humanenvironment system design [3]. Physical measurements in climatic chambers or in the field and numerical simulations using computational fluid dynamics (CFD) software are the two main methods for obtaining these factors [4]. Simulation is a more efficient method for the design and evaluation stage of indoor and vehicle cabin climate control since it allows for the fast generation of data for many scenarios, parametric optimization for the best performing solution, and carrying out sensitivity and robustness studies for choosing design approaches. Besides, it is not always possible to perform field tests in a full-scale building or a real car under repeatable weather conditions, while simulations can reproduce thermal environments and visualize the thermal interaction between these environments and occupants. Additionally, the separation of different heat transfer pathways is typically not practical in experiments or field studies, whereas it is a convenient practice with simulations. Such an analysis enhances the understanding of underlying physical phenomena and optimization of the modelled environments and scenarios [5]. Numerical simulation of realistic environments and the human body offers yet another opportunity for coupling a virtual human body built in the CFD environment with mathematical models of human thermoregulation, thermal sensation, and comfort (Cropper et al., 2010; Angelova et al., 2014; Lim et al., 2015; Voelker and Alsaad, 2018). In this way, the physiological and sensational human response to the designed environment can be simulated with high resolution and accuracy, given that the human response models are properly validated $[12,13]$. The accuracy of these mathematical models in the coupled system can be potentially enhanced since the CFD model accounts for the exact geometry and posture of the human body and the heat transfer at the body surface as opposed to predefined theoretical or empirical heat transfer coefficients in stand-alone human thermoregulation models, such as the Fiala model $[14,15]$ or the University of California, Berkeley (UCB) model [16].

Several numerical models for body-environment thermal interaction have been reported in the recent decade and are summarised in Table 1. They consider mainly a standing person in indoor space or a seated person in a vehicle cabin, whereas very few simulations have been reported for a person lying down, despite a growing interest for improving human thermal comfort during sleep. About one-third of studies dedicating the heat transfer characterization at the human body surface were carried out with simplified human body models. Although the development of computational technologies has made 3D full-scale simulation possible, consideration of the balance between computational cost and accuracy is often the underlying reason for the simplifications. Zhang et al. [5] studied the influence of body simplification on heat transfer based on CFD models and measurements available in the literature and found large differences between models with different levels of complexity as well as between physical manikins with comparable 
complexity. This is a typical issue when comparing data obtained in different studies and labs, where the model, simulation domain, and numerical method settings differ to some degree and it is difficult to attribute the discrepancy to only one factor. Furthermore, the accuracy of the existing simulation models is often not sufficiently proven since only half of the studies listed in Table 1 were validated by comparing their outcome to experimental data, but not always considering an identical setup configuration as used in the simulation. As CFD software simulates the non-isothermal flow between body and environment by coupling turbulent flow and heat transfer together, in principle, both the simulated air flow and heat flow should be validated against measurements with the same setup. Also, the simulation domain and the experimental chambers should not differ in size and wall properties, which may result in different radiation view factors and airflow patterns despite applying identical air speed. Among the numerical models that were claimed to be validated, Yang et al. (Yang et al., 2017) compared the simulated total sensible heat flux at the body surface under natural convection conditions to the measured data on a thermal manikin Monika [18] under the same air speed. Over $20 \mathrm{~W} / \mathrm{m}^{2}$ discrepancy in total heat flux between the simulation and measurement was observed at the upper and lower leg segments, which was supposedly related to slight differences in body geometry and pose, whereas Quintela et al. [19] reported up to only a 2.2\% change in the total heat transfer coefficient at the body surface for dramatic posture changes (standing, sitting, and lying). At the same time, the size and properties of the chambers for simulation and experiment in the study by Yang et al. were not matched and their effect on the radiation view factor and airflow was not discussed. In the study by $\mathrm{Li}$ [20], the forced convection between a seated human body and the environment was simulated and validated by comparison with measured values in a wind tunnel with the same setup. Although the measured and simulated convective heat transfer coefficients agreed well (5\% discrepancy for the side wind), no comparison and validation of the air speed and air temperature was performed. A considerable parameter validation was conducted in the studies by Mao et al. and Voelker et al. [6,21], which compared both air temperature and air speed between simulation and measurements in multiple points around the human body. Nonetheless, thermal radiation was unfortunately not considered in these two studies, which weakens the applicability of these models.

Table 1 Human body-environment interface heat transfer models in the recent decade.

\begin{tabular}{lllll}
\hline Study & Physics & Human geometry & $\begin{array}{l}\text { Human } \\
\text { posture }\end{array}$ & $\begin{array}{c}\text { Validated } \\
\text { parameter }\end{array}$ \\
\hline Voelker [6] & Conv & Scanned manikin & Seated & $\mathrm{T}_{\mathrm{a}}, \mathrm{V}_{\mathrm{a}}$ \\
Mao [21] & Conv & Scanned manikin & Lying & $\mathrm{T}_{\mathrm{a}}, \mathrm{V}_{\mathrm{a}}$ \\
Yang [8] & Conv/Rad & Scanned manikin & Standing & $\mathrm{Q}_{\mathrm{cov}}, \mathrm{Q}_{\mathrm{rad}}$ \\
& Conv & Scanned manikin & & \\
Alsaad [22] & & (slightly simplified) & & \\
& & & &
\end{tabular}




\begin{tabular}{|c|c|c|c|c|}
\hline Takada [23] & Conv & $\begin{array}{l}\text { Scanned human } \\
\text { body }\end{array}$ & Standing & $\mathrm{R}_{\mathrm{a}}$ \\
\hline Dixit [9] & Conv/Rad & $\begin{array}{l}\text { Scanned manikin } \\
\text { (slightly simplified) }\end{array}$ & Seated & - \\
\hline Li [20] & Conv & Scanned manikin & Seated & $\mathrm{h}_{\mathrm{c}}$ \\
\hline Angelova [10] & & $2 \mathrm{D}$ vase shape & Standing & - \\
\hline Martinho [24] & Conv/Rad & Scanned manikin & Seated & $\mathrm{T}_{\mathrm{a}}, \mathrm{V}_{\mathrm{a}}$ \\
\hline Pan [25] & Conv/Rad & $\begin{array}{l}\text { Scanned human } \\
\text { body }\end{array}$ & Lying & $\begin{array}{l}\mathrm{T}_{\mathrm{a}}, \mathrm{V}_{\mathrm{a}}, \mathrm{h}_{\mathrm{c}}, \\
\mathrm{h}_{\mathrm{r}}\end{array}$ \\
\hline Cropper [7] & Conv/Rad & Scanned manikin & Standing & \\
\hline Zhang [5] & Conv & $\begin{array}{l}\text { Scanned manikin/ } \\
\text { Blocks/Cylinders }\end{array}$ & Standing & - \\
\hline Kilic [26] & Conv/Rad/Mass & $\begin{array}{l}\text { Scanned manikin } \\
\text { (slightly simplified) }\end{array}$ & Standing & - \\
\hline Ono [27] & Conv & Scanned manikin & Standing & $\mathrm{h}_{\mathrm{c}}$ \\
\hline
\end{tabular}

Conv, convection; $R$ ad, radiation; $T_{a}$, air temperature; $Q_{c o v}$, convective heat; $Q_{\text {rad, }}$ radiative heat; $V_{a}$, air velocity; $h_{c}$, convective heat transfer coefficient; $h_{r}$, radiative heat transfer coefficient; $R_{a}$, the rate of air. Obtaining consistent validation data from the published literature is a challenging task. Large discrepancies between measured data using different thermal manikins can be observed, which makes cross validation of the CFD models a tough task. Figure 1 shows several datasets of overall and local heat transfer coefficients measured using anatomically-shaped thermal manikins - SAM [28], ANDI (unpublished data), Newton (Psikuta et al., 2015; unpublished data) measured in two different labs, Monika [18], Diana [28] and Tore [28] in precisely controlled climatic chambers under comparable conditions. The overall total heat transfer coefficient varied between 7.90 and $11.20 \mathrm{~W} /\left(\mathrm{m}^{2}{ }^{\circ} \mathrm{C}\right)$ (mean: $10.2 \mathrm{~W} /\left(\mathrm{m}^{2}{ }^{\circ} \mathrm{C}\right), \mathrm{SD}$ (standard deviation): 1.1 $\mathrm{W} /\left(\mathrm{m}^{2} \mathrm{C}\right)$, relative error: $\left.10.8 \%\right)$ with even larger local variations with the greatest values for the hand segment, varying between 5.5 and $15.2 \mathrm{~W} /\left(\mathrm{m}^{2}{ }^{\circ} \mathrm{C}\right)\left(\right.$ mean: $9.9 \mathrm{~W} /\left(\mathrm{m}^{2 \circ} \mathrm{C}\right), \mathrm{SD}: 3.0 \mathrm{~W} /\left(\mathrm{m}^{2 \circ} \mathrm{C}\right)$, relative error: $30.5 \%)$. The commonly used explanation for this uncertainty is the diversity in body geometry, body size, and body posture. Nonetheless, the variation between overall heat transfer coefficients in distinctly different manikin postures (lying, seated, and standing) measured in the same climatic chamber [19] was between 7.88 and $8.06 \mathrm{~W} /\left(\mathrm{m}^{2}{ }^{\circ} \mathrm{C}\right)$, which is remarkably less than that shown in Figure 1. Besides, both Newton and ANDI, as well as Diana and Monika, are the same type of manikins and still show remarkable differences. A more plausible explanation for these differences could be the local distribution of air speed in the proximity of the manikin, which was typically measured only in one spot in the manikin studies as a representative value for the entire manikin body surface and is reported without turbulence level values. 
Furthermore, radiative characteristics of the climatic chamber, such as wall emissivity and size related to area view factors for radiative heat exchange between manikin and walls, could be other important factors causing such a big discrepancy. These issues increase the complexity for a correct interpretation of the manikin data obtained in the climatic chambers to real-life applications, where the difference in wall emissivity in labs (typically polished metal with wall emissivity of 0.05 ) and real indoor occupational spaces (with wall emissivity of $0.93-0.95$ ) can be substantial.

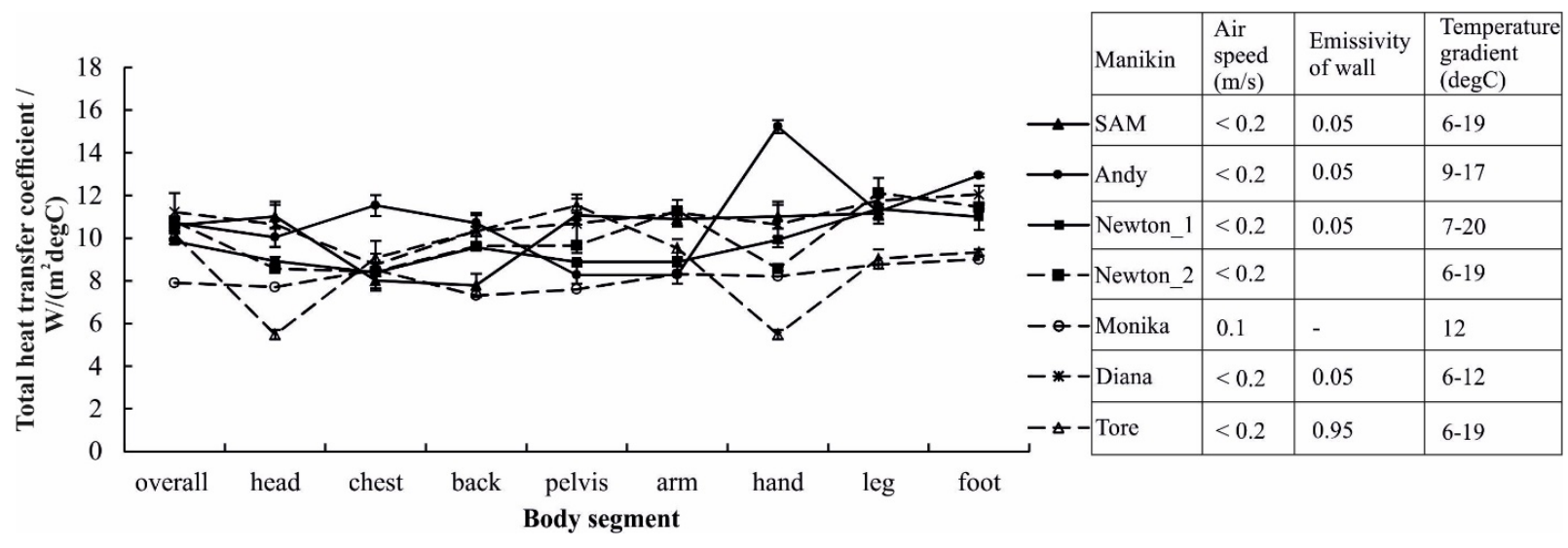

Fig.1. Total sensible heat transfer coefficients measured with different thermal manikins under similar environmental conditions in different laboratories $[18,28]$.

Therefore, the main aim of the study was the investigation of the influence of the human body and surrounding environment on heat loss from the body surface by a thoroughly validated numerical bodyenvironment interface model. Different human body geometries, body postures, room configurations, room sizes, and emissivity of the room wall were considered in the model, and their influence on the overall and local heat transfer was investigated. The simulation methodology was verified for three essential parameters, including air speed distribution in the environment, temperature profile in the proximity of the body surface, and heat transfer coefficient at the body surface, which were measured in the climatic chamber with identical dimensions and equipped with a thermal manikin. The dataset of heat transfer coefficients obtained from the simulations can contribute to an increased precision of human thermoregulation models, and the model itself can serve as a validated interface between a model of human thermal physiology and the environment constructed in CFD technology.

\section{Methodology}

\subsection{Design of the study}

To address the shortcomings of the simulation studies reported in the literature, this study began with the development and systematic step-by-step verification of the CFD simulation model before attempting any further analysis (including the human body and its surrounding environment). First, thermal flow experiments between a thermal manikin and the surrounding environment were performed inside a climatic 
chamber (chamber 1). Then, the chamber geometry was reproduced exactly in the numerical simulation using COMSOL Multiphysics 5.3a (COMSOL, Inc., USA), and fluid flow and heat transfer simulations between the manikin and the chamber were performed. A comprehensive set of simulated results, such as air temperatures, air speeds, and heat loss at numerous locations in the chamber, in the proximity of the manikin and on the thermal manikin was compared with the measured results to verify the modelling approach.

The second part included three parametric studies addressing issues relevant for accurate simulation of human body interaction with its thermal environment. For a more generic outcome of these studies, a simplified rectangular-shaped virtual chamber (chamber 2) with a human body model inside was created based on the verified simulation method. The parametric studies included the following:

Study 1 - investigation of the influence of the body geometry simplification on the heat transfer coefficient by comparing two simplified geometries with one anatomically shaped human body geometry. These shapes are commonly used as human body representation in human thermoregulation models and manikins simulating human occupancy in building research.

Study 2 - investigation of the influence of body posture change on the heat transfer coefficient by comparing three different body postures, including a standing posture, a seated posture, and a lying posture. All body geometries were obtained by 3D scanning of an anatomically shaped physical manikin. These body postures involve potential changes in daily heat transfer conditions at the body surface and are most common in simulation of human occupancy and activities in many disciplines.

Study 3 - investigation of the influence of the surrounding environment, such as room configuration, room size, and wall emissivity on heat transfer coefficients at the human body as a necessary issue to consider when transferring the experimental results from the small chamber with typical polished-metal walls to a real-life occupational space.

\subsection{Measurements for the validation of the numerical simulation method in chamber 1}

The validation measurements were conducted in the climatic chamber reproduced in the COMSOL software as chamber 1 (length: $6.3 \mathrm{~m}$, width: $3.5 \mathrm{~m}$, height: $2.4 \mathrm{~m}$,) with the air flow arrangement shown in Fig. $2 \mathrm{a}$ and the thermal manikin SAM with 22 independently controlled sectors standing in the centre, $8.5 \mathrm{~cm}$ above the floor (Fig.3a). Each sector of the manikin can be heated at a constant average surface temperature or with a constant power. In the experiment, the thermal manikin surface temperature was uniformly controlled at $34 \pm 0.1^{\circ} \mathrm{C}$ by adjusting the heating power. This heating power of individual manikin sectors was assumed equivalent to the heat loss from the manikin body. The air temperature and the relative humidity of the chamber were kept constant at $23 \pm 0.2^{\circ} \mathrm{C}$ and $50 \pm 5 \%$, respectively. The air speed at the inlet of the chamber and at 39 sites at five different height levels in the chamber (Fig.6) was measured using omnidirectional anemometers (Sensor Electronic, SENSOANEMO 5100SF, accuracy: $\pm 0.02 \mathrm{~m} / \mathrm{s} \pm 1 \%$, Fig. $3 \mathrm{~b}$ ). The 
temperature distribution in the proximity of the manikin surface was also obtained using a setup of six mini thermistors (EPCOS, India, width: $1.3 \pm 0.2 \mathrm{~mm}$, length: $2.2 \pm 0.4 \mathrm{~mm}$, calibration accuracy: $\pm 0.2^{\circ} \mathrm{C}$ ), which were distributed at a distance of $0.1-14 \mathrm{~cm}$ from the manikin surface, as shown in Fig.3c. The six-thermistor setup was placed next to the different body segments (side upper arm, front upper leg, chest, back, back head) to record the temperature distribution in the adjacent air layer in the front, side, and back of the manikin and at different height levels. The heat flux at the manikin surface was recorded continuously for one hour after the steady state was reached, and the average value for the recorded one hour was calculated. All measurements were repeated three times. The measured air speed at the inlet was applied as the inlet boundary condition for the simulation. The remaining experimental results, such as air speed at 39 sites in the chamber, air temperature near the manikin surface at 6 body parts, and the heat flux from the manikin surface, were compared with the corresponding results from the simulation.
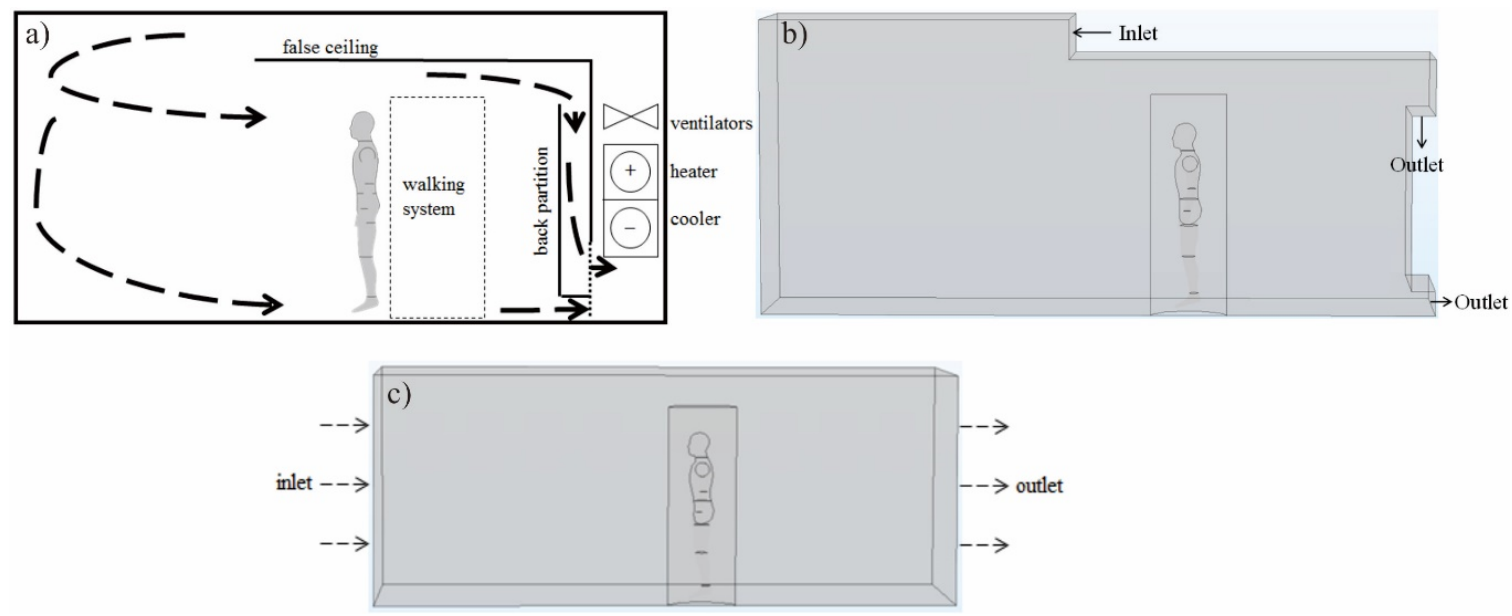

Fig.2. Sketch of a) the physical climatic chamber 1, b) virtual chamber 1 used for verification of the model and, c) virtual chamber 2 used for parametric studies.
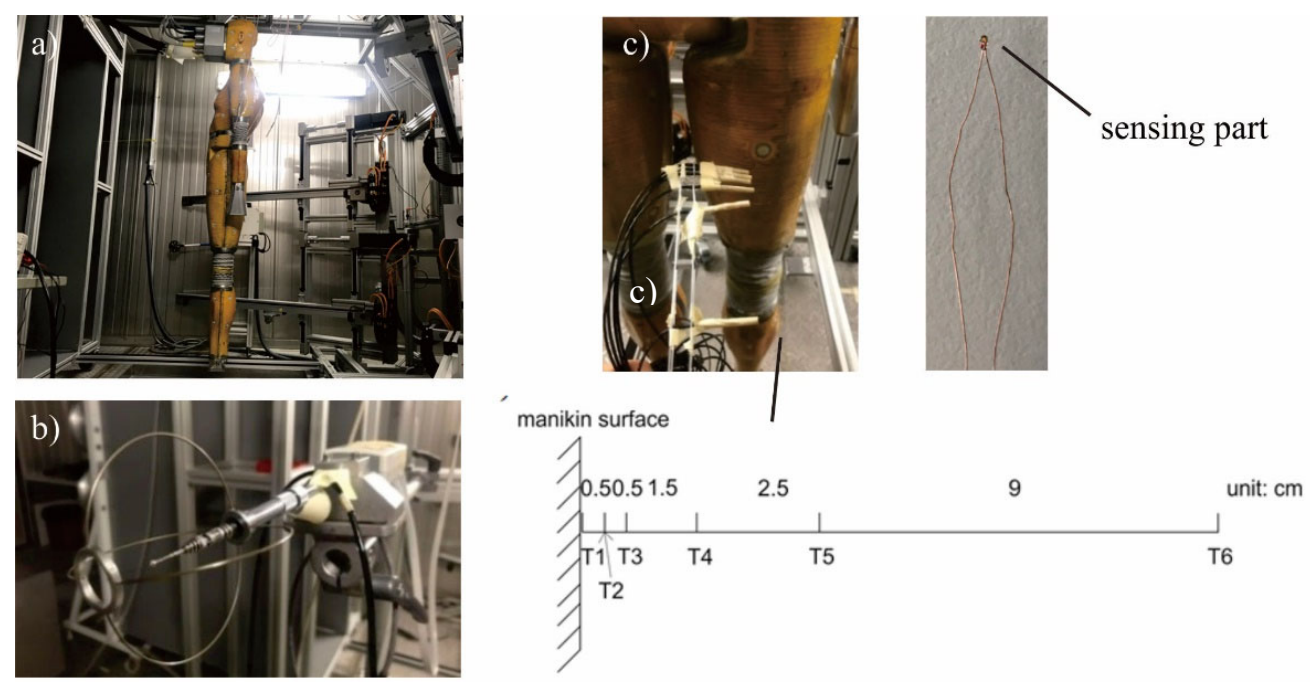
Fig.3. Physical measurement setup in climatic chamber 1. a) Chamber configuration with a thermal manikin standing inside, b) anemometer for air speed measurement, and c) thermistor setup placed next to manikin surface for air temperature measurement (e.g. front upper leg).

\section{3 .Numerical simulation of validation conditions in chamber 1}

The climatic chamber reproduced in COMSOL Multiphysics 5.3a (COMSOL, Inc., USA) included one inlet and two air outlets and the thermal manikin simulated by an anatomically shaped model of the human body (Fig. 2b). To reduce the computational cost, the symmetric boundary function offered by COMSOL was used to simulate only half of the domain. Further, the computational domain was divided into two meshing regions (near the manikin body and the rest of the domain, Fig.2b). The tetrahedral domain mesh, triangular surface mesh, and 5-layer boundary layer mesh were generated for both regions. The mesh (Figure 4) near the manikin body (the maximum mesh size is $22 \mathrm{~mm}$ ) was denser than that in the rest region (the maximum mesh size is $280 \mathrm{~mm}$ ). Mesh sensitivity was checked with regards to the total heat flux from the manikin surface, as heat flux is the most sensitive parameter to the number of mesh elements compared to air speed in the chamber and air temperature near manikin surface. Around 1.71 million domain mesh elements were finally employed for the simulation as a further increase of mesh number from 1.71 million resulted in less than $0.5 \%$ change in heat flux and even smaller improvement in air speed and temperature in manikin surface proximity. Table 2 lists the physical models and boundary conditions used in the numerical model of the validation study.
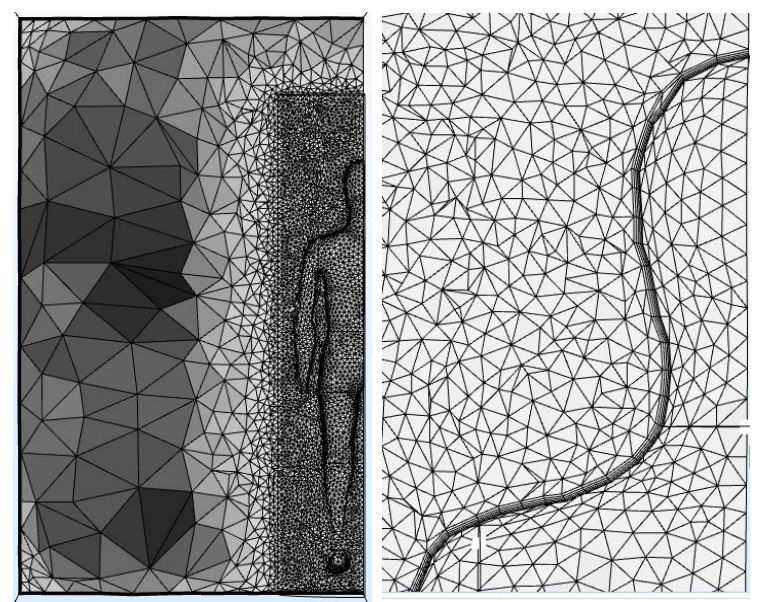

Fig.4 Left: Front view of the mesh with denser cells around the manikin; Right: boundary layer mesh around the head and shoulder of scanned man Table 2 Model settings of the simulation for validation.

\begin{tabular}{llllllll}
\hline $\begin{array}{l}\text { Turbulence } \\
\text { model }\end{array}$ & $\begin{array}{l}\text { Radiation } \\
\text { model }\end{array}$ & $\begin{array}{l}\text { Wall } \\
\text { emissivity }\end{array}$ & $\begin{array}{l}\text { Manikin surface } \\
\text { temperature }\end{array}$ & $\begin{array}{l}\text { Inlet air and } \\
\text { wall temperature }\end{array}$ & $\begin{array}{l}\text { Inlet air } \\
\text { velocity }\end{array}$ & Outlet & $\mathrm{x}_{1}{ }^{*}$ \\
\hline $\mathrm{k}-\varepsilon$ & $\begin{array}{l}\text { Surface to } \\
\text { surface }\end{array}$ & 0.05 & $34^{\circ} \mathrm{C}$ & $23^{\circ} \mathrm{C}$ & $0.89 \mathrm{~m} / \mathrm{s}$ & pressure & $\begin{array}{l}0.8 \\
\mathrm{~mm}\end{array}$ \\
\hline
\end{tabular}


$x_{1} *$ is the thickness of the first of the five-boundary layer mesh next to the chamber wall and manikin surface (expansion ratio of 1.2).

\subsection{Comparison between measurements and the numerical simulation in chamber 1}

\section{Air speed in the chamber}

The air speed at five height levels in the chamber was obtained from the simulation and compared with the measured values at 39 points at the same height levels. The average SD and the average RMSD (root mean square deviation) values at five height levels, as well as the exact air speed values at H3 and H4 levels, are presented in Fig. 4. Generally, the simulated results agree very well with the measurements when comparing SD and RMSD, within less than $0.1 \mathrm{~m} / \mathrm{s}$, except at the feet level (H5), where the simulated air speed was significantly higher than in the measurements $(\mathrm{RMSD}=0.19 \mathrm{~m} / \mathrm{s})$. This effect probably results from the metal frame of the wind tunnel and the manikin walking system hindering the airflow close to the floor in the physical climatic chamber (as shown in Fig. 3a), which was not considered in the simulation.

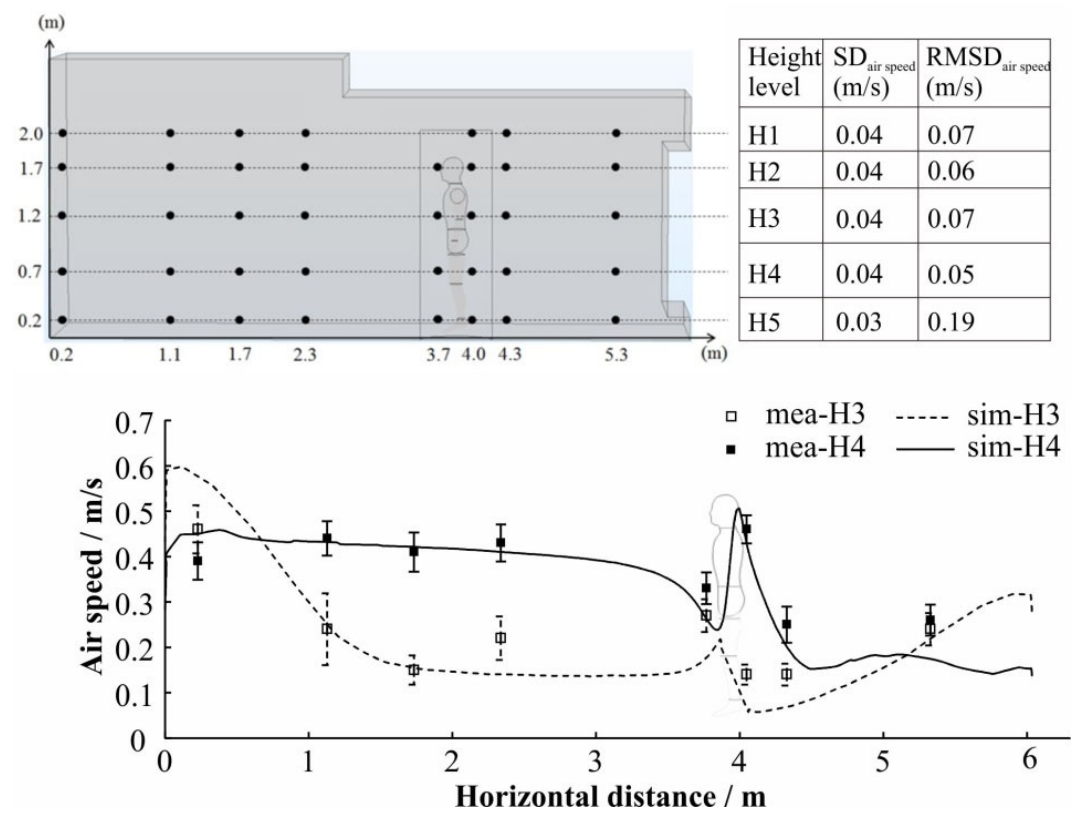

Fig.4. Measured and simulated air speeds in chamber 1 at most relevant height levels H3 and H4, as well as SD and RMSD at all height levels measured.

Air temperature near the manikin surface

The simulated air temperature in the proximity of the manikin surface was compared to the corresponding values from the measurements. The air temperature near three exemplary body surfaces at the back head, side upper arm, and front upper leg, which represent different height levels and orientations, as well as SD values and RMSD values of the air temperature near all the measured body segments, are presented in Fig.5. A sharp change in air temperature around $10^{\circ} \mathrm{C}$ was observed in the first one and a half centimetre. Then, 
the air temperature gradually changed more and became stable after about a 4-cm distance. The simulated air temperature was exactly within the error range of measurements at the front upper leg segment. In the proximity of the back head and side upper arm, the simulated air temperatures were also within the error range of measurements after $1 \mathrm{~cm}$, while within the first $1 \mathrm{~cm}$ they decreased faster than the measurements, especially for the back head. This can probably be explained by the cables attached to the manikin face in the real chamber (as shown in Fi.3a), which hinder thermal flow around the manikin's head. Also, at the top of the manikin, the thermal plume developed and was thickest in the proximity of head. The discrepancies in the simulation of the free convective flow along the manikin height possibly cumulate at the head level, creating a higher possibility to observe great discrepancy there.

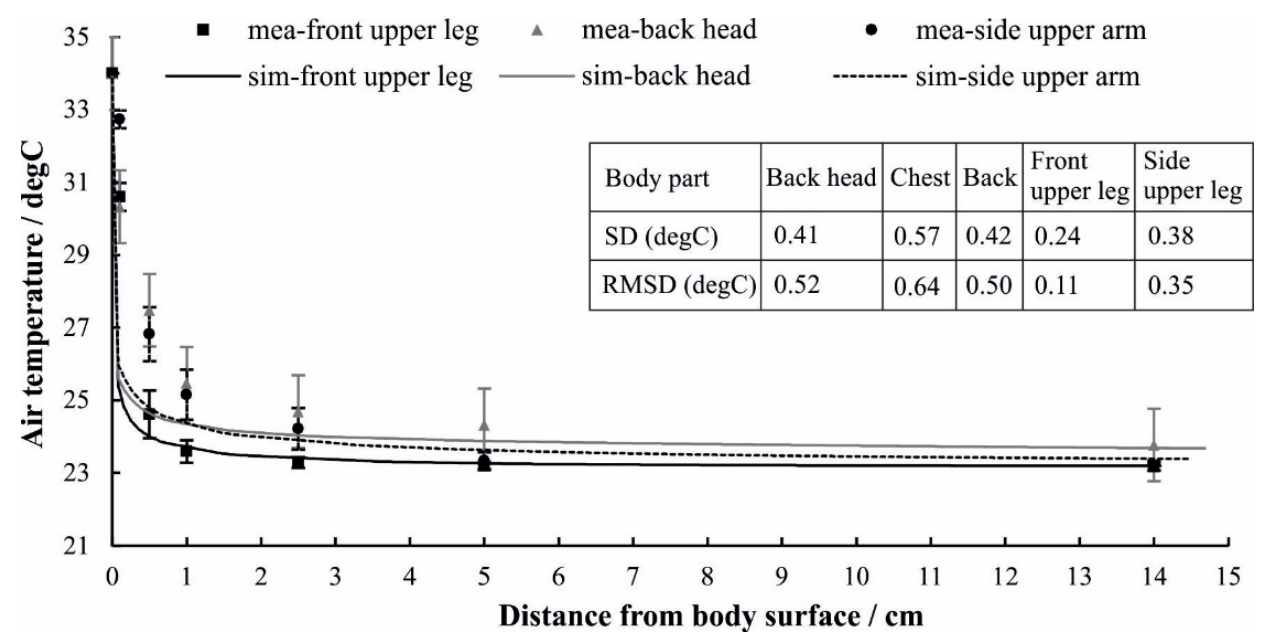

Fig.5. Measured and simulated air temperatures near the back head, side upper arm, and front upper leg, as well as SD and RMSD for all the body parts measured.

\section{Sensible heat transfer coefficient at the manikin surface}

Based on the simulated sensible heat flux from the manikin's surface, the sensible heat transfer coefficients were calculated. They are presented in Fig.6 $(\operatorname{sim} 0)$, along with the measured data from the manikins considered (Fig.1). However, only data from manikins SAM, ANDI, Newton_1, and Newton_2 is given. They show the highest comparability with $\operatorname{sim} 0$ because they had either the same body shape but different climatic chamber for Newton_2 or the same climatic chamber but different body shape for SAM, ANDI, and Newton_1, as in sim0 (some framing and pieces of equipment were present in the chamber but not simulated, which could locally influence the airflow). Except at the hand, foot, and leg, the simulated data is within the spread of the measurements, which indicates good cross validation of this numerical model. The high simulated total heat transfer coefficients at the hand, leg, and foot could be caused by the higher simulated air speeds than the measurements at $\mathrm{H} 4$ and H5 height levels (Fig.4) in the proximity of lower body surface caused by the manikin frame and equipment at the floor in front of the manikin. 


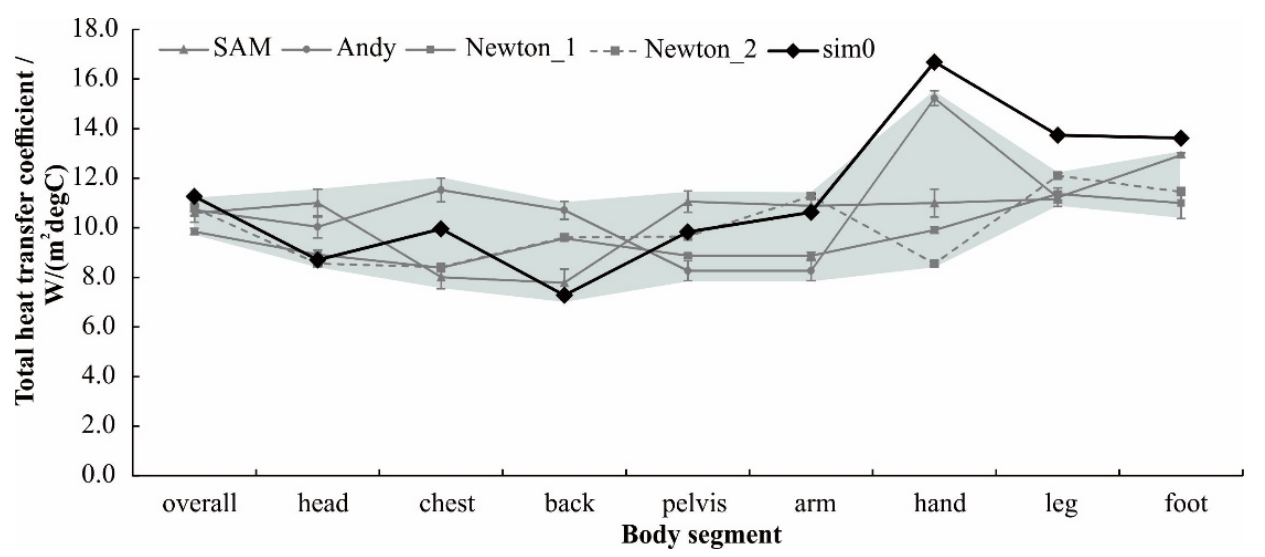

Fig.6. Simulated and measured total heat transfer coefficients using manikin SAM and different manikin historical data (Newton_2 - the same body shape but different climatic chamber, SAM, ANDI, and Newton_1 - the same climatic chamber but different body shapes than used in $\operatorname{sim} 0$ ).

\subsection{Virtual human body and environment for parametric studies in chamber 2}

Three standing virtual human body models, along with a seated and a lying version of the most realistic model, were built for the investigation of the influence of body geometry and body posture on heat transfer (Table 3). A cylinder subdivided into three parts is the simplest way of representing the human body, which is often used in mathematical models, such as the two-node Gagge model [29] and the cylinder model proposed by $\mathrm{Xu}$ et al. [30,31]. The second body geometry chosen for this study is composed of one sphere and thirteen cylinders, which resembles more closely the real human body shape than the cylinder, and it was built in accordance with the passive system dimensions of the thermoregulation model by Fiala et al. [14]. The third one is a scanned and processed model of the manikin Newton_Asia (Measurement Technology Northwest, Seattle, WA, USA) using a 3D scanner (Handyscan 700, resolution: $0.05 \mathrm{~mm}$, precision: $0.03 \mathrm{~mm}$ ) and surface inspection software (Geomagic Qualify, Geomagic Inc., North California, USA). A seated human body model was also obtained using the 3D scanning of the same manikin in a seated posture and a lying posture, originated from rotating the standing scanned manikin model.

To make the numerical model more applicable for researchers in different fields, a simplified wind tunnelshaped virtual chamber 2 (Figure 2c; length: $6.0 \mathrm{~m}$, width: $4.0 \mathrm{~m}$, height: $2.7 \mathrm{~m}$ ) was built for the representation of a generic indoor occupational space. The virtual human bodies were placed $3.37 \mathrm{~m}$ away from the inlet of the chamber, and they were floating $8.5 \mathrm{~cm}$ above the floor.

Table 3 Detailed information of the virtual human body models.

\begin{tabular}{|c|c|c|c|c|}
\hline \multicolumn{2}{|c|}{ Virtual human body model } & \multirow[b]{2}{*}{ Body segments } & \multirow{2}{*}{$\begin{array}{l}\text { Body } \\
\text { height }\end{array}$} & \multirow{2}{*}{$\begin{array}{l}\text { Body } \\
\text { surface } \\
\text { area }\end{array}$} \\
\hline Name & Sketch & & & \\
\hline
\end{tabular}




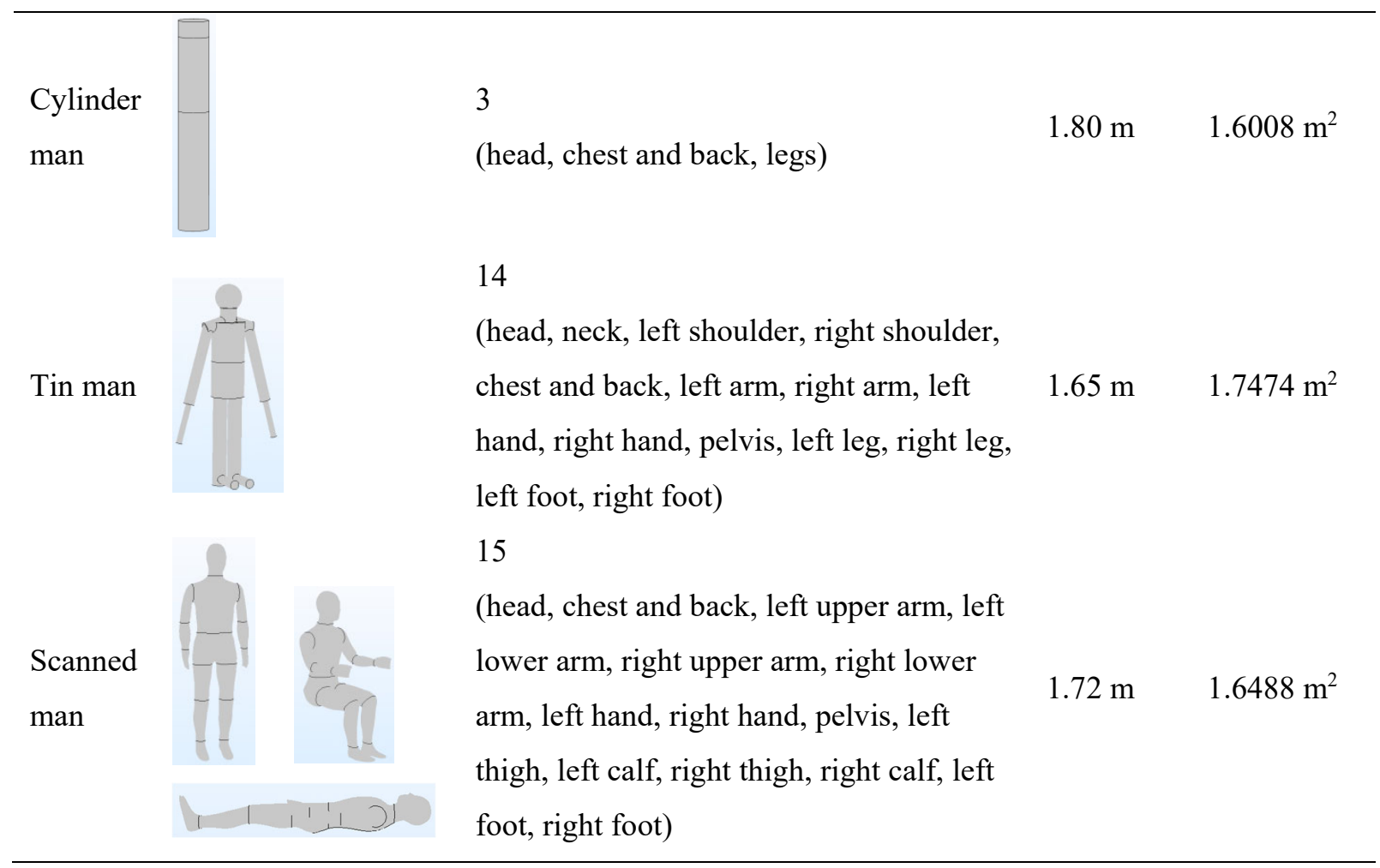

\subsection{Numerical method for parametric studies in chamber 2}

In total, seven simulations were designed and conducted for the investigation of the influence of human body geometry, human body posture, and the surrounding environment (room configuration, room size, and wall emissivity) on heat transfer. Table 4 lists the boundary condition settings for each of the seven simulations. Sim7, which aims to investigate the influence of room size on heat transfer, was conducted in a slightly bigger chamber (length: $9.0 \mathrm{~m}$, width: $6.0 \mathrm{~m}$, height: $3.0 \mathrm{~m}$ ) transformed based on virtual chamber 2 , with the same distance between manikin and inlet.

According to the simulation method verified in section 2.3 , the $\mathrm{k}-\varepsilon$ model and surface-to-surface radiation model were used for turbulence flow and radiation simulation, respectively. The wall function was automatically employed using the k- $\varepsilon$ model. The settings for the boundary layer mesh and skin surface mesh were also defined according to the verified simulation of chamber 1 . An inlet air velocity of $0.2 \mathrm{~m} / \mathrm{s}$ was set in order to get natural airflow.

The convective $\left(\mathrm{q}_{\mathrm{c}}\right)$ and radiative heat flux $\left(\mathrm{q}_{\mathrm{r}}\right)$ at the manikin surface were obtained by computing the simulations using COMSOL. The total heat transfer coefficient $\left(\mathrm{h}_{\mathrm{t}}\right)$, convective heat transfer coefficient $\left(\mathrm{h}_{\mathrm{c}}\right)$, and radiative heat transfer coefficient $\left(\mathrm{h}_{\mathrm{r}}\right)$ were then calculated by dividing the flux by the temperature gradient between the manikin surface and environment. The impact of body geometry, body posture, room configuration, room size, and wall emissivity on heat transfer from the body surface to the environment was investigated by comparing $h_{t}, h_{c}$, and $h_{r}$ between relevant simulations, as indicated in Table 4 . 
Table 4 Boundary conditions of the simulations for parametric studies.

\begin{tabular}{|c|c|c|c|c|c|c|c|}
\hline $\begin{array}{l}\text { Simu- } \\
\text { lation } \\
\text { No. }\end{array}$ & $\begin{array}{l}\text { Inlet air } \\
\text { velocity } \\
(\mathrm{m} / \mathrm{s})\end{array}$ & $\begin{array}{l}\text { Skin and air } \\
\text { temperatures } \\
\left({ }^{\circ} \mathrm{C}\right)\end{array}$ & $\begin{array}{l}\text { No. of } \\
\text { mesh } \\
\text { elements }\end{array}$ & $\begin{array}{l}\text { Wall } \\
\text { emissivity } \\
(\varepsilon)\end{array}$ & $\begin{array}{l}\text { Body } \\
\text { geometry }\end{array}$ & $\begin{array}{l}\text { Body } \\
\text { posture }\end{array}$ & Investigated factor \\
\hline $\operatorname{sim} 1$ & \multirow{9}{*}{0.2} & \multirow{9}{*}{34,22} & $1.73 \mathrm{M}$ & 0.93 & cylinder man & standing & Study 1: Body \\
\hline $\operatorname{sim} 2$ & & & $1.22 \mathrm{M}$ & 0.93 & tin man & standing & geometry ( $\operatorname{sim} 1$, \\
\hline $\operatorname{sim} 3$ & & & $1.55 \mathrm{M}$ & 0.93 & scanned man & standing & $\operatorname{sim} 2, \operatorname{sim} 3)$ \\
\hline $\operatorname{sim} 4$ & & & $2.76 \mathrm{M}$ & 0.93 & scanned man & seated & Study 2: Body \\
\hline $\operatorname{sim} 5$ & & & $0.97 \mathrm{M}$ & 0.93 & scanned man & lying & posture $(\operatorname{sim} 3, \operatorname{sim} 4$, \\
\hline $\operatorname{sim} 6$ & & & $1.55 \mathrm{M}$ & 0.05 & scanned man & standing & sim5) \\
\hline \multirow{3}{*}{$\operatorname{sim} 7$} & & & & & & & $\begin{array}{l}\text { Study } 3 \text { : Room } \\
\text { configuration ( } \operatorname{sim} 0 \\
\text { and } \operatorname{sim} 6)\end{array}$ \\
\hline & & & $1.68 \mathrm{M}$ & 0.93 & scanned man & standing & $\begin{array}{l}\text { Study 3: Room size } \\
(\operatorname{sim} 3 \text { and } \operatorname{sim} 7)\end{array}$ \\
\hline & & & & & & & $\begin{array}{l}\text { Study } 3 \text { : Wall } \\
\text { emissivity ( } \operatorname{sim} 3 \text { and } \\
\operatorname{sim} 6)\end{array}$ \\
\hline
\end{tabular}

\section{Results}

\subsection{Study 1: Heat transfer coefficients from different human body geometries}

Fig.7 shows the simulated overall and local heat transfer coefficients (total, convective, and radiative) at the body surface of the cylinder man, tin man, and scanned man. For the cylinder man, as the chest, back, arm, pelvis, and hand segments are simplified as one single cylinder partitioned into an anterior sector and a posterior sector, the values for the chest and back segments were derived from the anterior and posterior sectors, respectively, and the values for the arm, pelvis, and hand segments were assigned as the average value from the anterior and posterior sectors. The minimum and maximum data from the measured datasets according to Fig.1 is also given in Fig. 7. Fig. 8 shows the air temperature distribution around the human body models for different body geometries from both front and side views. 

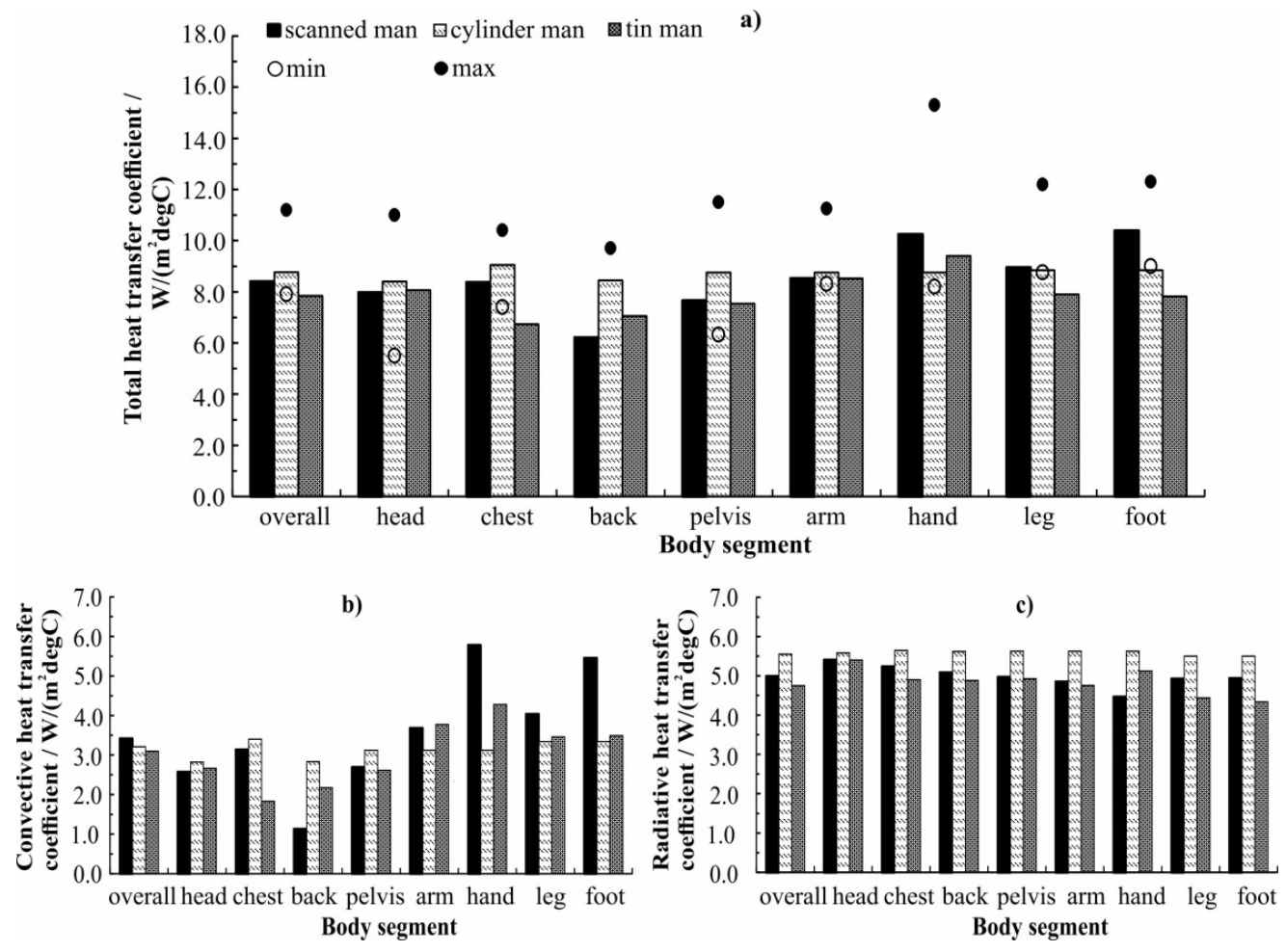

Fig. 7. Simulated overall and local heat transfer coefficients for different body geometries; a) total heat transfer coefficient, along with the minimum and maximum data from previous manikin measurements shown in Fig. 1, b) convective heat transfer coefficient, and c) radiative heat transfer coefficient.

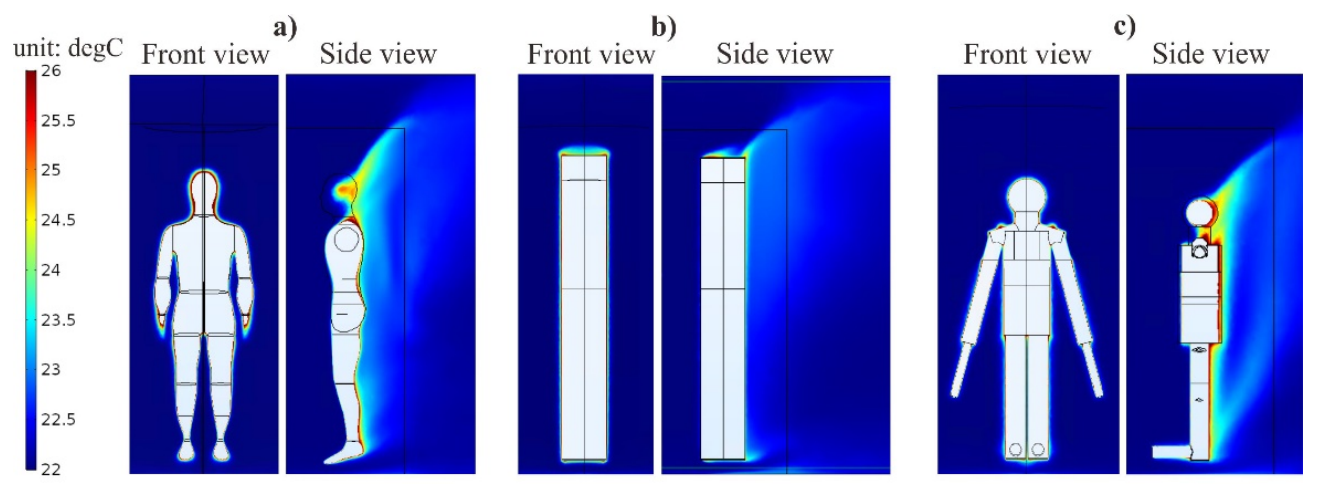

Fig. 8. Air temperature distribution around the a) scanned man, b) cylinder man, and c) tin man from front and side views.

\subsection{Study 2: Heat transfer coefficients in different human body postures}

Fig. 9 presents the simulated overall and local heat transfer coefficients at the scanned man body surface for standing, seated, and lying postures. Fig. 10 shows the simulated air temperature distribution around the scanned man body surface in different postures in both front (top) and side views. 

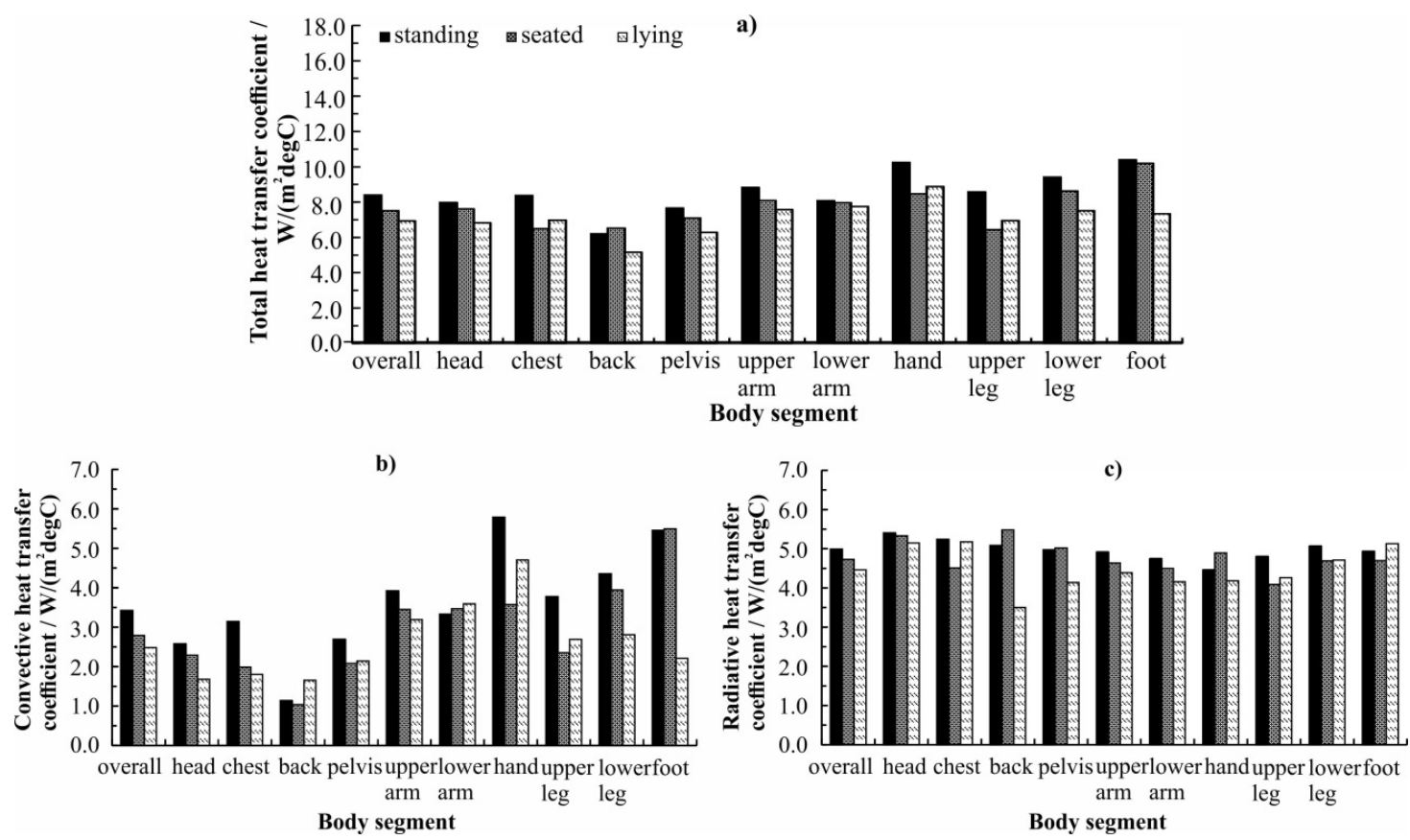

Fig. 9. Simulated overall and local heat transfer coefficients at the scanned man surface in different postures, a) total heat transfer coefficient, b) convective heat transfer coefficient, and c) radiative heat transfer coefficient.

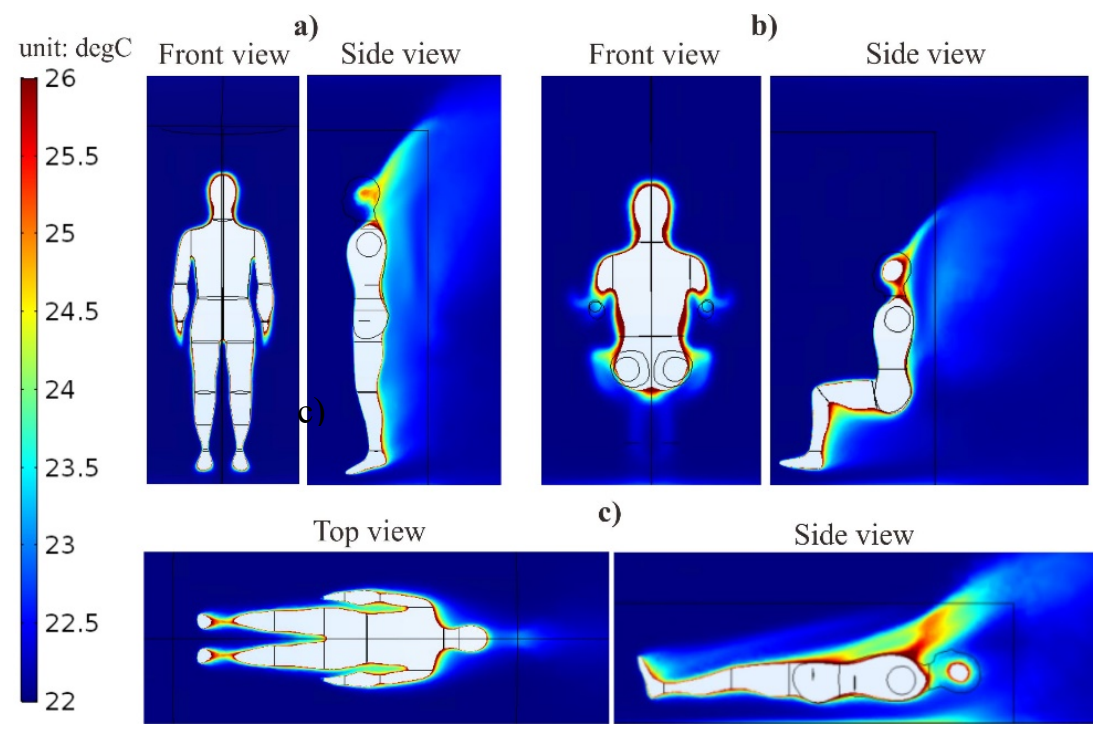

Fig. 10. Air temperature distribution around the scanned man for a) standing, b) seated, and c) lying postures in front (top) and side views.

\section{3 .Study 3: Heat transfer coefficients from the human body in different surrounding environments}

Fig. 11 shows the simulated overall and local heat transfer coefficients from the scanned man surface in different surrounding environments, such as $\operatorname{sim} 3$ (chamber $2, \varepsilon=0.93$ ), $\operatorname{sim} 0$ (chamber $1, \varepsilon=0.05$ ), sim6 
(chamber 2, $\varepsilon=0.05$ ), and $\operatorname{sim} 7$ (larger chamber 2, $\varepsilon=0.93$ ). The influence of room configuration, which affects the air flow pattern (comparing $\operatorname{sim} 0$ and sim6), room size (comparing sim 3 and $\operatorname{sim} 7$ ), and wall emissivity (comparing $\operatorname{sim} 3$ and sim6) on heat transfer, can be observed by comparing respective datasets.
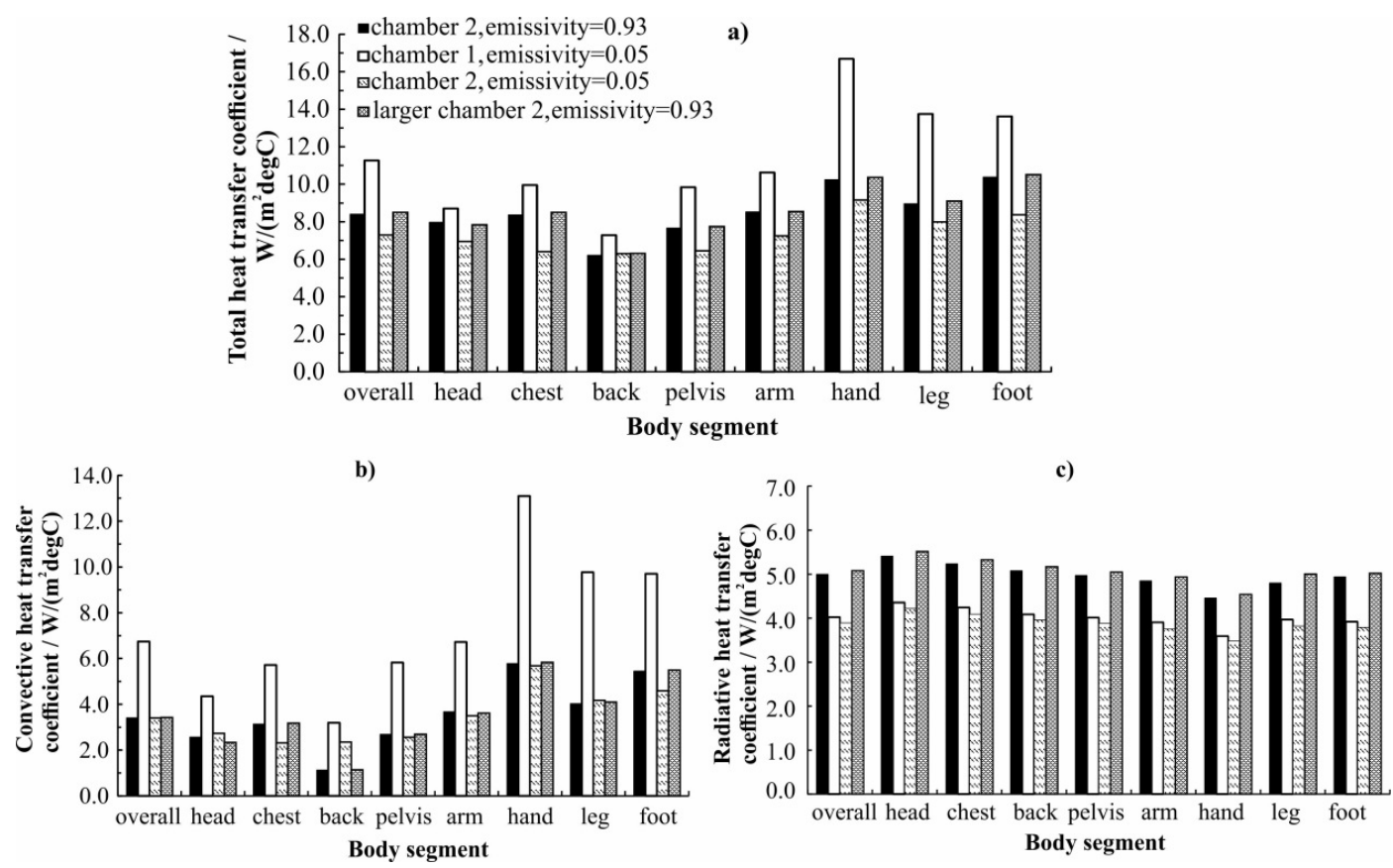

Fig. 11. Simulated overall and local heat transfer coefficients from the scanned man surface in four different environments, a) total heat transfer coefficient, b) convective heat transfer coefficient, and c) radiative heat transfer coefficient.

\section{Discussion}

\subsection{Influence of human body geometry simplification on the heat transfer coefficient}

To find the balance between model simplification and predicted accuracy, a comparison of heat transfer properties between human body geometries with different simplification levels, such as the scanned man, tin man, and cylinder man, which were typically used in thermoregulation models and lab measurements, was performed. As a fully anatomically shaped model, the scanned man is considered a basic reference for the tin man and cylinder man and is supposed to show the most equivalent heat transfer properties compared to measurements with full-scale manikins. For the total heat transfer coefficient $\left(\mathrm{h}_{\mathrm{t}}\right.$, Fig. 7a), the simulated data for the body parts was within the measured data spread of the manikin, except the back with $h_{t}$, which was lower than the minimum measured data by $1.1 \mathrm{~W} /\left(\mathrm{m}^{2}{ }^{\circ} \mathrm{C}\right)$. Variations in $\mathrm{h}_{\mathrm{t}}$ were observed as the human body was simplified into the cylinder man and tin man. For the overall $\mathrm{h}_{\mathrm{t}}$, the differences between body geometries were small and within $\pm 0.6 \mathrm{~W} /\left(\mathrm{m}^{2}{ }^{\circ} \mathrm{C}\right)(4.2 \%$ higher value for the cylinder man and $6.7 \%$ lower value for the tin man compared to the scanned man). 
Locally, for the cylinder man, $h_{t}$ at the trunk (chest, back, and pelvis) was $8.0-36.0 \%\left(0.6-2.2 \mathrm{~W} /\left(\mathrm{m}^{2}{ }^{\circ} \mathrm{C}\right)\right.$ ) higher than that of the scanned man. According to Fig. $7 \mathrm{~b}$ and $\mathrm{c}$, the higher values come from both the convective heat transfer coefficient $\left(\mathrm{h}_{\mathrm{c}}\right)(8.4-15.9 \%)$ and the radiative heat transfer coefficient $\left(\mathrm{h}_{\mathrm{r}}\right)(7.8-$ $13.3 \%$ ). For the $h_{c}, 8.4-150.2 \%$ higher values were found at the trunk, with the greatest difference found at the back. It seems that the smooth cylinder-shaped body surface of the cylinder man made the thermal flow over the body surface more fluent than at the curved body surface of the scanned man, resulting in greater heat loss. A measurement study by Zukowska et al [32] comparing the thermal plume above four seated thermal manikins with different geometry simplification levels also proposed the simplified smooth body geometry without legs would cause less realistic thermal plume than a real manikin. The existence of limbs and its impact on thermal plume cannot be disregarded. With regards to the radiative heat transfer, the whole surface of the cylinder man was exposed to the surrounding radiation field and, therefore, had a $100 \%$ effective radiation area, while the effective radiation area for an anatomic body is generally assumed to be around $73 \%$ as some body parts face each other [33]. Thus, higher values of $h_{r}$ were found at every body segment for the cylinder man compared to the scanned man. For the limbs, the discrepancy in $h_{t}$ between the cylinder man and the scanned man was within $\pm 0.2 \mathrm{~W} /\left(\mathrm{m}^{2}{ }^{\circ} \mathrm{C}\right)$. However, the discrepancies for both heat transfer coefficients, $h_{c}$ (Fig. 7b) and $h_{r}$ (Fig. 7c), show remarkably different values (a lower value of $h_{c}$ by $0.56-0.69 \mathrm{~W} /\left(\mathrm{m}^{2}{ }^{\circ} \mathrm{C}\right)$ and a higher value of $\mathrm{h}_{\mathrm{r}}$ by $0.58-0.78 \mathrm{~W} /\left(\mathrm{m}^{2}{ }^{\circ} \mathrm{C}\right)$ at arm and leg segments of the cylinder man compared to the scanned man). For the lower $h_{c}$ at the arm, the possible reason could be related to the area-weighted calculation. As there is actually no arm in the cylinder man, $\mathrm{h}_{\mathrm{c}}$ at the arm was an areaweighted value of the chest and back of the cylinder man. According to the values given by the scanned man, the chest and back parts originally had lower $h_{c}$ values than the arm. A lower $h_{c}$ value at the arm segment of the cylinder man would thus occur.

For the tin man, which simplifies the human body into thirteen cylinders and one sphere, less of a difference from the scanned man in convective and radiative heat exchange with the environment was expected due to the presence of actual limbs compared to the cylinder man. Nonetheless, some differences in the course of buoyancy air flow around the body were observed. According to the air temperature distribution around the tin man (Fig.8c) and the scanned man (Fig.8a), the thermal plume building up at the leg of the tin man was blocked by the bottom part of the pelvis (cylinder representing pelvis segment that is two times larger in radius than the leg cylinder connected to it at the bottom), while it smoothly continued along the trunk of the scanned man. Much more heat was gathered behind the leg of the tin man than the scanned man, which resulted in $14 \%$ and $36 \%$ lower $h_{c}$ values at the leg and foot of the tin man, respectively. Besides, higher air speed was found at the back of the tin man $(0.12 \mathrm{~m} / \mathrm{s})$ than for the scanned man $(0.09 \mathrm{~m} / \mathrm{s})$, which contributed to the higher $h_{c}$ values at the back of the tin man (Fig.7b), probably related to the hollow lower back of the scanned man that dissipated the buoyancy flow and, hence, reduced the air speed. 
In terms of radiative heat loss, the tin man provided values near the scanned man on overall $h_{r}$ and local $h_{r}$, except at the hand and foot, compared to cylinder man (Fig. 7c). This local discrepancy ( $h_{r}$ higher by $14.8 \%$ at the hand and lower by $12.2 \%$ at the foot) plausibly resulted from the difference in effective radiation area at these particular body parts. The hand palm, which accounts for almost half of the hand area, was facing the warm leg in the scanned man, while in the tin man it was mostly exposed to the radiation field of the surrounding walls as a thin and long cylinder $(31 \mathrm{~cm}$ length and $2.6 \mathrm{~cm}$ radius). For the foot, this phenomenon was reversed, where the sole and instep of the scanned man was mostly exposed to surrounding environments as opposed to two long and slim cylinders facing each other in the tin man.

In summary, if only the overall thermal property instead of the local thermal property of a human body is of interest, a simplified cylinder man would be effective for total and convective heat transfer studies and would be helpful in reducing model complexity and computational cost, while risking overestimating radiative heat transfer by $11 \%$. The tin man, which has an identical construction as the simplified human body used by the Fiala model [14], was proven to also be effective when the regional thermal properties were not considered. However, the complexity of the body geometry increases the difficulty for meshing work and computational cost while doing numerical simulation. Thus, the body geometry of the tin man is suggested only for analytical modelling. An anatomic human body model is always the best choice for heat transfer studies when thermal properties of local body parts are of importance.

Body geometry was addressed by previous studies as one of the factors creating differences in heat transfer properties when comparing measurements and models. However, those measurements and models are not always ideally comparable due to differences in the environmental setup [8]. The heat transfer coefficients on different human body geometries, which were typically used in the physical measurements and modelling work, were obtained based on the same environmental condition and simulation method in this study. This ensures that body geometry is the only changing variable, making the heat transfer properties acquired on different body geometries completely comparable.

\subsection{Influence of human body posture on the heat transfer coefficient}

In different body postures, such as standing, seating, and lying, the different body part orientations and areas contribute to a varying buoyancy flow and radiative effective area.

According to Fig. 9, both convective and radiative heat transfer coefficients at the scanned man surface decreased for seating and lying postures compared to the standing body. The overall $h_{c}$ and $h_{r}$ decreased by $18.4 \%\left(0.63 \mathrm{~W} /\left(\mathrm{m}^{2}{ }^{\circ} \mathrm{C}\right)\right)$ and $5.2 \%\left(0.26 \mathrm{~W} /\left(\mathrm{m}^{2}{ }^{\circ} \mathrm{C}\right)\right)$, respectively, for the seated posture and by $27.4 \%(0.94$ $\left.\mathrm{W} /\left(\mathrm{m}^{2}{ }^{\circ} \mathrm{C}\right)\right)$ and $10.6 \%\left(0.53 \mathrm{~W} /\left(\mathrm{m}^{2}{ }^{\circ} \mathrm{C}\right)\right)$, respectively, by for the lying posture. As a combined effect of convective heat and radiative heat, the overall $\mathrm{h}_{\mathrm{t}}$ decreased by $10.6 \%\left(0.89 \mathrm{~W} /\left(\mathrm{m}^{2}{ }^{\circ} \mathrm{C}\right)\right)$ for the seated posture and by $17.5 \%\left(1.47 \mathrm{~W} /\left(\mathrm{m}^{2}{ }^{\circ} \mathrm{C}\right)\right)$ for the lying posture. These differences between body postures $(0.89-1.47$ $\left.\mathrm{W} /\left(\mathrm{m}^{2}{ }^{\circ} \mathrm{C}\right)\right)$ are two to three times greater compared to the differences in overall $\mathrm{h}_{\mathrm{t}}$ caused by body geometry 
simplification shown in Fig. $7\left(-0.56-0.35 \mathrm{~W} /\left(\mathrm{m}^{2}{ }^{\circ} \mathrm{C}\right)\right)$. Therefore, the body posture seems to have a more significant influence on heat transfer than the chosen body simplification.

For the seated posture, as the body parts below the knee remained at the same position as in the standing posture, little change in convective heat transfer could be expected at the lower leg and foot. Indeed, less than $10 \%$ discrepancy $\left(0.41 \mathrm{~W} /\left(\mathrm{m}^{2}{ }^{\circ} \mathrm{C}\right)\right)$ in $\mathrm{h}_{\mathrm{c}}$ (Fig. $\left.9 \mathrm{~b}\right)$ at the lower leg and foot segments of the scanned man was observed between standing and seated postures. For the rest of the body parts, as their orientation and height in the room changed between standing and seated postures, the thermal plume development around them changed as well, as indicated in the air temperature distribution shown in Fig. 10. A large decrease in $\mathrm{h}_{\mathrm{c}}$ by $22.7-38.3 \%\left(0.61-2.21 \mathrm{~W} /\left(\mathrm{m}^{2}{ }^{\circ} \mathrm{C}\right)\right)$ was found at the pelvis, chest, hand, and upper leg parts of the seated scanned man when compared with the standing scanned man.

When the scanned man was lying, the orientation of all body segments changed entirely compared to the standing position. The airflow was directed from the feet to the head of the scanned man and the thermal plume developed across the body circumference and along the anterior parts, as is shown in Fig. 10c. In this case, the $h_{c}$ values decreased even more than for the seated posture, by $18.6-59.5 \%\left(0.56-3.24 \mathrm{~W} /\left(\mathrm{m}^{2}{ }^{\circ} \mathrm{C}\right)\right)$ at all body parts except for the lower arm and back (Fig9b). The greatest drop of $59.5 \%\left(3.24 \mathrm{~W} /\left(\mathrm{m}^{2}{ }^{\circ} \mathrm{C}\right)\right.$ ] was observed at the foot, which might be explained by the accumulation of heat rising by the buoyancy force at the lower leg and heating the instep due to airflow being blocked by the sole.

Considering the thermal radiation between the human body and the environment, different view factors between body parts (especially chest, arms, and legs) between standing and seated postures are expected to influence $\mathrm{h}_{\mathrm{r}}$. For example, the upper leg of the seated scanned man, which faced cooler walls, was perpendicular to the warm chest and lower leg and, thus, gained more radiative heat from these segments than in the standing posture $\left(\mathrm{h}_{\mathrm{r}}\right.$ for seated posture decreased by $0.71 \mathrm{~W} /\left(\mathrm{m}^{2}{ }^{\circ} \mathrm{C}\right)(14.9 \%)$. Similarly, a $\mathrm{h}_{\mathrm{r}}$ value lower by $0.73 \mathrm{~W} /\left(\mathrm{m}^{2}{ }^{\circ} \mathrm{C}\right)(13.9 \%)$ was found at the chest in the seated posture.

As the scanned man was lying $8.5 \mathrm{~cm}$ over the floor, the warm posterior part of the body was very close to the cool floor, resulting in $4^{\circ} \mathrm{C}$ higher temperature of the floor than in the standing case. Thus, $31.0 \%[1.58$ $\left.\mathrm{W} /\left(\mathrm{m}^{2}{ }^{\circ} \mathrm{C}\right)\right)$ and $16.7 \%\left(0.83 \mathrm{~W} /\left(\mathrm{m}^{2}{ }^{\circ} \mathrm{C}\right)\right)$ decreases in $\mathrm{h}_{\mathrm{r}}$ were found at the back and pelvis parts, respectively. The influence of body posture on heat transfer found in this study was partially consistent with findings from previous experimental studies [18,19] on sensible heat transfer exchange from the manikins Monika and Maria in different postures. On the one hand, lower overall $h_{c}$ and $h_{r}$ and higher local $h_{c}$ values at the lower arm were found for the seated posture compared to the standing posture. The manikin Maria had a higher $\left(5.7 \%, 0.21 \mathrm{~W} /\left(\mathrm{m}^{2 \circ} \mathrm{C}\right)\right) \mathrm{h}_{\mathrm{c}}$ in the lying posture compared to the standing posture, which is contrary to the scanned man. Such an inconsistency could be attributed to the difference in the environmental settings, which were unfortunately not clearly reported in the study by de Dear et al. 


\subsection{Influence of the surrounding environment on the heat transfer coefficient}

Considering the possible influence of the environment on the heat transfer properties, total, convective, and radiative heat transfer coefficients at the scanned man's surface were obtained in four different environments with changing air flow patterns, size of the room, and emissivity of wall.

For the changing air flow organisation, the results from chamber 1 used in the validation study and generic chamber 2 from the parametric studies were compared (in both cases $\varepsilon=0.05$ with only a slight difference in size). Although both cases represented very close average volume air speeds in the small cylinder domain (shown in Fig.2) around the scanned man $(0.27 \mathrm{~m} / \mathrm{s}$ for chamber 1 and $0.19 \mathrm{~m} / \mathrm{s}$ for chamber 2), different local air speed profiles were observed (Fig.12a and b)), especially below the height of the pelvis. Also, different thermal plum phenomena were observed (Fig.12 c) and d). This led to some remarkable discrepancies in $\mathrm{h}_{\mathrm{c}}$ (Fig.11b), with the greatest at the hand $\left(7.41 \mathrm{~W} /\left(\mathrm{m}^{2}{ }^{\circ} \mathrm{C}\right)\right)$, leg $\left(5.60 \mathrm{~W} /\left(\mathrm{m}^{2}{ }^{\circ} \mathrm{C}\right)\right)$, and foot $\left(5.11 \mathrm{~W} /\left(\mathrm{m}^{2}{ }^{\circ} \mathrm{C}\right)\right)$. This could explain the large differences between $\mathrm{h}_{\mathrm{t}}$ shown in Fig.1, measured on manikins in different labs. The same average air speed around the human body, based on a few measured points in different labs, does not ensure the same airflow pattern and is likely to cause different convective heat transfer properties. In the case of the different chamber size (chamber 2 and larger chamber $2, \varepsilon=0.93$ ) with the same air flow organisation, no substantial difference in $h_{c}$ was found at the scanned man's surface, as expected $\left(-0.24-0.07 \mathrm{~W} /\left(\mathrm{m}^{2}{ }^{\circ} \mathrm{C}\right)\right.$, Fig. $\left.11 \mathrm{~b}\right)$. The $\mathrm{h}_{\mathrm{r}}$ value increased slightly in the larger chamber $2(0.08-$ $\left.0.11 \mathrm{~W} /\left(\mathrm{m}^{2}{ }^{\circ} \mathrm{C}\right)\right)$ due to changes in view area factors of the body while towards larger walls (Fig. 11c). 


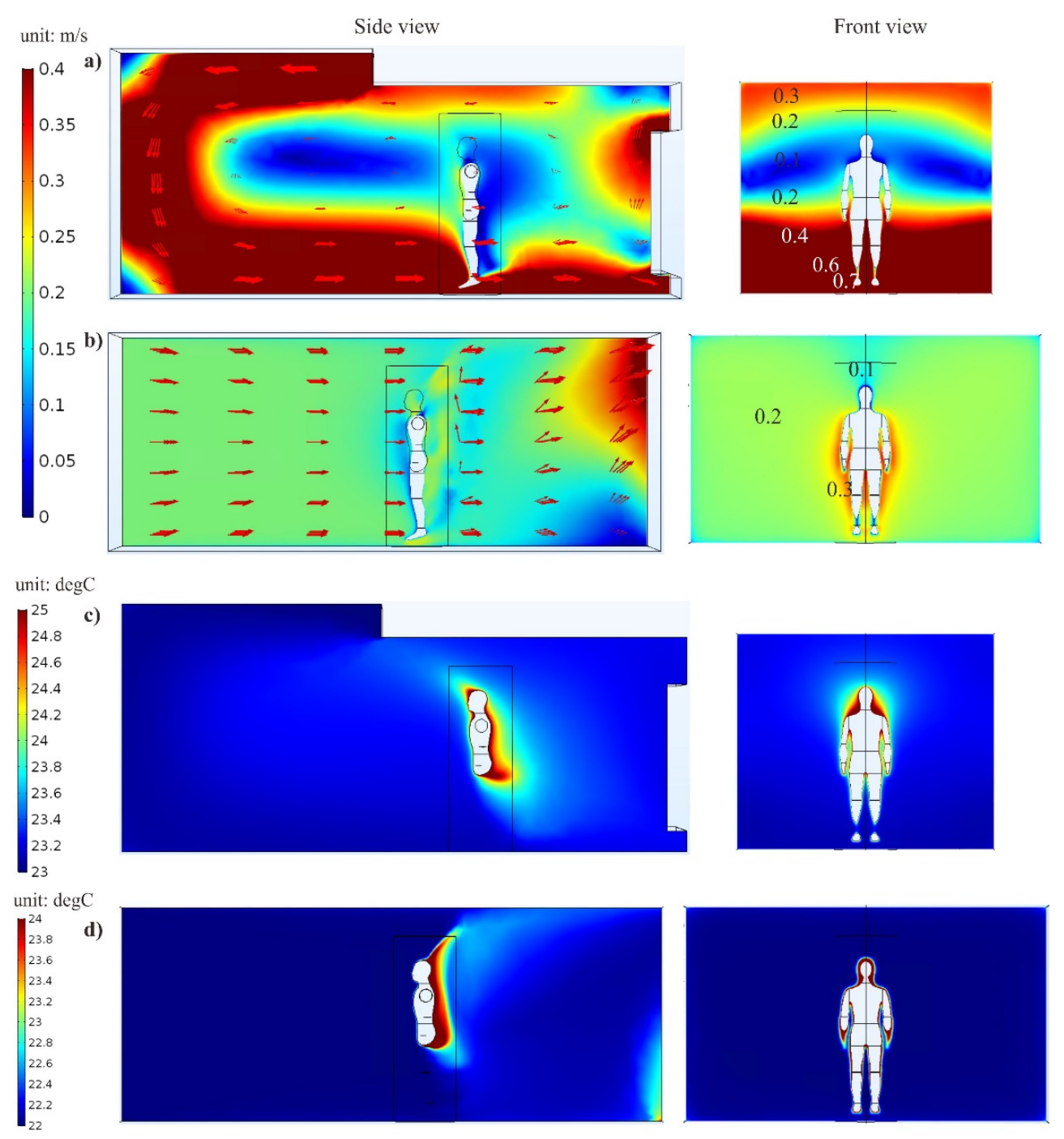

Fig.12. Airflow pattern in a) chamber $1(\varepsilon=0.05)$ and $b)$ in chamber $2(\varepsilon=0.05)$, as well as air temperature distribution in c) chamber $1(\varepsilon=0.05)$ and $d)$ in chamber $2(\varepsilon=0.05)$ from the side view and front view. (The legend of air speed in a) and b) was set from 0 to $0.4 \mathrm{~m} / \mathrm{s}$ to make the airflow change more visible.)

The comparison of chambers with the same wall emissivity indicated that the radiative heat transfer coefficient will only negligibly change even if the airflow organisation and room size change and as long as the wall emissivity remains the same (Fig.11c). The radiative heat transfer coefficient of the whole human body was around $5.0 \mathrm{~W} /\left(\mathrm{m}^{2}{ }^{\circ} \mathrm{C}\right)$ in a typical indoor room $(\varepsilon=0.93)$, which is close to the value of 4.7 $\mathrm{W} /\left(\mathrm{m}^{2}{ }^{\circ} \mathrm{C}\right)$, considered a reasonable whole-body estimate for general purposes in the ASHARE Handbook of Fundamentals [34]. However, this value decreased to $3.9 \mathrm{~W} /\left(\mathrm{m}^{2}{ }^{\circ} \mathrm{C}\right)$ (drop by $22 \%$ ) in a climatic chamber with steel-lined walls $(\varepsilon=0.05)$. Furthermore, as the radiative heat accounts for nearly $60 \%$ of the total sensible heat flux under natural air flow conditions (according to both our study and the study by Kilic et al. (Kilic and Sevilgen, 2008)), the total 13\% underestimation of the sensible heat flux will consequently be observed. Although it was theoretically known that surface emissivity has an impact on radiative heat 
transfer, this rather large quantified difference reveals the need for careful interpretation of results obtained in steel-lined climatic chambers for to typical occupational spaces in real life.

\section{Conclusions}

In this study, we developed a numerical method for simulating heat transfer between the human body surface and the environment using the CFD software COMSOL Multiphysics. Successful validation of this method was performed by comparing the simulated air speed in the environment (RMSD: $0.05-0.19 \mathrm{~m} / \mathrm{s}$ at five height levels), the air temperature in the proximity of the human body surface (RMSD: $0.11-0.64^{\circ} \mathrm{C}$ ), and the sensible heat transfer coefficients from the body surface with the corresponding measured values in a climatic chamber with the same configuration.

With the validated numerical method, the influences of body geometry simplification, body posture, and the surrounding environment on overall and local heat transfer coefficients at the body surface were investigated. The simplification of body geometry had only a moderate influence on the overall heat transfer coefficient $\left(-0.56-0.36 \mathrm{~W} /\left(\mathrm{m}^{2 \circ} \mathrm{C}\right)\right)$, but a remarkably larger influence on the local heat transfer coefficients $(-1.71-1.50$ $\mathrm{W} /\left(\mathrm{m}^{2}{ }^{\circ} \mathrm{C}\right)$ ). Human body posture changes had more prominent influences on total heat transfer coefficients than human body geometry simplifications, with the highest difference of $3.05 \mathrm{~W} /\left(\mathrm{m}^{2}{ }^{\circ} \mathrm{C}\right)$ found at the foot. The room configuration greatly influenced the air flow configuration and consequently had a large influence (over 50\%) on convective heat transfer from the body surface. The room size was found to have very little impact on convective heat and radiative heat, while wall emissivity highly influenced radiative heat (22\% discrepancy in radiative heat and $13 \%$ in total sensible heat between a typical indoor wall and a steel-lined climatic chamber wall). Thus, inclusion of an anatomic human body shape for heat transfer studies is suggested only where local physiological effects and thermal sensation are of particular interest. Future modelling of human thermoregulation should also consider human body posture for obtaining more accurate predictions. A comparable room configuration and airflow pattern is the premise for conducting comparisons between heat transfer studies in different labs or simulations. Additionally, based on the comparisons between body geometries, it is recommended for verification work to validate both convective heat and radiative heat loss whenever feasible since a good match of total sensible heat loss can be composed of underestimation and overestimation of individual heat transfer mechanisms. The modelling/simulation approach, along with the human body-environment interface models validated in this study can be used for coupling with the human thermoregulation model so that a complete numerical thermal manikin can be built with thermoregulation algorithms governing skin temperature and sweat rate.

\section{Acknowledgements}

The authors would like to acknowledge the Fundamental Research Funds for the Central Universities (Grant NO. 2232019G-08) and Graduate Student Innovation Fund of Donghua University (Grant NO. 08CUSF- 
DH-D-2019098), the financial support from Shanghai Municipal Natural Science Foundation (Grant NO. 17ZR1400500), and the National Key Research and Development Plan (Grant NO. 2017YFB0309100). The part of this work was supported by the HEAT-SHIELD project within the EU Horizon 2020 program, under grant no. RIA 668786-1.

\section{References}

[1] W. Pasut, H. Zhang, E. Arens, Y. Zhai, Energy-efficient comfort with a heated/cooled chair: Results from human subject tests, Build. Environ. 84 (2015) 10-21. doi:10.1016/j.buildenv.2014.10.026.

[2] A. Psikuta, J. Allegrini, B. Koelblen, A. Bogdan, S. Annaheim, N. Martínez, D. Derome, J. Carmeliet, R.M. Rossi, Thermal manikins controlled by human thermoregulation models for energy efficiency and thermal comfort research - A review, Renew. Sustain. Energy Rev. (2017). doi:10.1016/j.rser.2017.04.115.

[3] B. Koelblen, A. Psikuta, A. Bogdan, S. Annaheim, R.M. Rossi, Thermal sensation models: a systematic comparison, Indoor Air. 27 (2017). doi:10.1111/ina.12329.

[4] D. Wölki, C. Van Treeck, Y. Zhang, S. Stratbücker, S.R. Bolineni, A. Holm, Individualisation of virtual thermal manikin models for predicting thermophysical responses, in: 12th Int. Conf. Indoor Air Qual. Clim. 2011, 2011: pp. 432-437. https://www.scopus.com/inward/record.url?eid=2-s2.084880522948\&partnerID=40\&md5=c12245e0ca149944f550be087372c2f9.

[5] Y. Zhang, D. Novieto, Y. Ji, Human environmental heat transfer simulation with CFD - the advances and challenges, in: Elev. Int. IBPSA Conf., Glasgow, 2009: pp. 2162-2168. http://usir.salford.ac.uk/15849/.

[6] C. Voelker, H. Alsaad, Simulating the human body's microclimate using automatic coupling of CFD and an advanced thermoregulation model, Indoor Air. 28 (2018) 415-425. doi:10.1111/ina.12451.

[7] P. Cropper, T. Yang, M. Cook, D. Fiala, R. Yousaf, Coupling a model of human thermoregulation with computational fluid dynamics for predicting human-environment interaction., J. Build. Perform. Simul. 3 (2010) 233-243. doi:10.1080/19401491003615669.

[8] J. Yang, S. Ni, W. Weng, Modelling heat transfer and physiological responses of unclothed human body in hot environment by coupling CFD simulation with thermal model, Int. J. Therm. Sci. 120 (2017) 437-445. doi:10.1016/j.ijthermalsci.2017.06.028. 
[9] A. Dixit, U. Gade, A case study on human bio-heat transfer and thermal comfort within CFD, Build. Environ. 94 (2015) 122-130. doi:10.1016/j.buildenv.2015.07.016.

[10] R.A. Angelova, G. Pichurov, I. Simova, P. Stankov, I. Rodrigo, CFD based study of thermal sensation of occupants using thermophysiological model. Part I, Int. J. Cloth. Sci. Technol. 26 (2014) 442-455. doi:10.1108/IJCST-10-2013-0116.

[11] J. Lim, H. Choi, E.K. Roh, H. Yoo, E. Kim, Assessment of airflow and microclimate for the running wear jacket with slits using CFD simulation, Fash. Text. 2 (2015) 1. doi:10.1186/s40691014-0025-2.

[12] A. Psikuta, D. Fiala, G. Laschewski, G. Jendritzky, M. Richards, K. Blazejczyk, I. Mekjavič, H. Rintamäki, R. de Dear, G. Havenith, Validation of the Fiala multi-node thermophysiological model for UTCI application, Int. J. Biometeorol. 56 (2012) 443-460. doi:10.1007/s00484-011-0450-5.

[13] B. Koelblen, A. Psikuta, A. Bogdan, S. Annaheim, R.M. Rossi, Thermal sensation models: Validation and sensitivity towards thermo-physiological parameters, Build. Environ. 130 (2018) 200-211. doi:10.1016/j.buildenv.2017.12.020.

[14] D. Fiala, K.J. Lomas, M. Stohrer, A computer model of human thermoregulation for a wide range of environmental conditions: the passive system, J. Appl. Physiol. 87 (1999) 1957-1972.

[15] D. Fiala, K. Lomas, M. Stohrer, Computer prediction of human thermoregulatory and temperature response to a wide range of environmental conditions, Int. J. Biometeorol. 45 (2001) 143-159. doi:10.1007/s004840100099.

[16] C. Huizenga, H. Zhang, E. Arens, A model of human physiology and comfort for assessing complex thermal environments, Build. Environ. 36 (2001) 691-699. https://doi.org/10.1016/S0360-1323(00)00061-5.

[17] P.C. Cropper, T. Yang, M.J. Cook, D. Fiala, R. Yousaf, Exchange of simulation data between CFD programmes and a multi- segmented human thermal comfort model, Proc. Conf. Air Cond. Low Carbon Cool. Chall. (2008) 27-29. http://nceub.org.uk.

[18] R.J. de Dear, E. Arens, Z. Hui, M. Oguro, Convective and radiative heat transfer coefficients for individual human body segments., Int. J. Biometeorol. 40 (1997) 141-156. doi:10.1007/s004840050035.

[19] D. Quintela, A. Gaspar, C. Borges, Analysis of sensible heat exchanges from a thermal manikin, Eur. J. Appl. Physiol. 92 (2004) 663-668. doi:10.1007/s00421-004-1132-3. 
[20] C. Li, K. Ito, Numerical and experimental estimation of convective heat transfer coefficient of human body under strong forced convective flow, J. Wind Eng. Ind. Aerodyn. 126 (2014) 107117. doi:10.1016/j.jweia.2014.01.003.

[21] N. Mao, M. Song, D. Pan, S. Deng, Computational fluid dynamics analysis of convective heat transfer coefficients for a sleeping human body, Appl. Therm. Eng. 117 (2017) 385-396. doi:10.1016/j.applthermaleng.2017.02.012.

[22] H. Alsaad, C. Voelker, CFD Assessment of Thermal Comfort and Indoor Air Quality Using Ductless Personalized Ventilation, 15th IBPSA Conf. (2017) 273-281. doi:https://doi.org/10.26868/25222708.2017.076.

[23] S. Takada, A. Sasaki, R. Kimura, Fundamental study of ventilation in air layer in clothing considering real shape of the human body based on CFD analysis, Build. Environ. 99 (2016) 210220. doi:10.1016/j.buildenv.2016.01.028.

[24] N. Martinho, A. Lopes, M. Gameiro da Silva, Evaluation of errors on the CFD computation of air flow and heat transfer around the human body, Build. Environ. 58 (2012) 58-69. doi:10.1016/j.buildenv.2012.06.018.

[25] D. Pan, M. Chan, S. Deng, L. Xia, X. Xu, Numerical studies on the microclimate around a sleeping person and the related thermal neutrality issues, Ergonomics. 54 (2011) 1088-1100. doi:10.1080/00140139.2011.611896.

[26] M. Kilic, G. Sevilgen, Modelling airflow, heat transfer and moisture transport around a standing human body by computational fluid dynamics, Int. Commun. Heat Mass Transf. 35 (2008) 11591164. doi:10.1016/j.icheatmasstransfer.2008.05.006.

[27] T. Ono, S. Murakami, R. Ooka, T. Omori, Numerical and experimental study on convective heat transfer of the human body in the outdoor environment, J. Wind Eng. Ind. Aerodyn. 96 (2008) 1719-1732. doi:10.1016/j.jweia.2008.02.007.

[28] A. Psikuta, K. Kuklane, A. Bogdan, G. Havenith, S. Annaheim, R.M. Rossi, Opportunities and constraints of presently used thermal manikins for thermo-physiological simulation of the human body., Int. J. Biometeorol. (2015) 435-446. doi:10.1007/s00484-015-1041-7.

[29] A.P. Gagge, J.A.. Stolwijk, Y. Nishi, An effective temperature scale based on a simple model of human physiological regulatory response, Ashrae Trans. 77 (1971) 247-262. 
[30] X. Xu, P. Tikuisis, R. Gonzalez, G. Giesbrecht, Thermoregulatory model for prediction of longterm cold exposure, Comput. Biol. Med. 35 (2005) 287-298.

doi:10.1016/j.compbiomed.2004.01.004.

[31] X. Xu, J. Werner, A Dynamic Model of the Humall/Clothing/EnvirorlInent -System., Appl. Hum. Sci. J. Physiol. Anthropol. 16 (1997) 61-75. doi:10.2114/jpa.16.61.

[32] D. Zukowska, A. Melikov, Z. Popiolek, Impact of geometry of a sedentary occupant simulator on the generated thermal plume: Experimental investigation, HVAC R Res. 18 (2012) 795-811. doi:10.1080/10789669.2012.672925.

[33] P.O. Fanger, Thermal comfort. Analysis and applications in environmental engineering, 1970.

[34] R. and A.C.E. American Society of Heating, Handbook, A.S.H.R.A.E, Atlanta, 2009. 